\title{
Structural basis of a shared antibody response to SARS-CoV-2
}

\author{
Meng Yuan ${ }^{1 *}$, Hejun Liu' ${ }^{1 *}$, Nicholas C. Wu' ${ }^{1 *}$ Chang-Chun D. Lee', Xueyong Zhu', Fangzhu Zhao ${ }^{2,3,4}$, \\ Deli Huang ${ }^{2}$, Wenli Yu', Yuanzi Hua', Henry Tien', Thomas F. Rogers ${ }^{2,5}$, Elise Landais ${ }^{2,3,6}$, Devin Sok ${ }^{3,4,6}$, \\ Joseph G. Jardine ${ }^{3,6}$, Dennis R. Burton ${ }^{2,3,4,7}$, Ian A. Wilson ${ }^{1,3,4,8+}$ \\ ${ }^{1}$ Department of Integrative Structural and Computational Biology, The Scripps Research Institute, La Jolla, CA 92037, USA. ${ }^{2}$ Department of Immunology and Microbiology, \\ The Scripps Research Institute, La Jolla, CA 92037, USA. ${ }^{3}$ IAVI Neutralizing Antibody Center, The Scripps Research Institute, La Jolla, CA 92037, USA. ${ }^{4}$ Consortium for \\ HIV/AIDS Vaccine Development (CHAVD), The Scripps Research Institute, La Jolla, CA 92037, USA. ${ }^{5}$ Division of Infectious Diseases, Department of Medicine, University of \\ California, San Diego, La Jolla, CA 92037, USA. ${ }^{6}$ IAVI, New York, NY10004, USA. ${ }^{7}$ Ragon Institute of Massachusetts General Hospital, Massachusetts Institute of Technology, \\ and Harvard University, Cambridge, MA 02139, USA. ${ }^{8}$ The Skaggs Institute for Chemical Biology, The Scripps Research Institute, La Jolla, CA, 92037, USA. \\ *These authors contributed equally to this work.
}

†Corresponding author. Email: wilson@scripps.edu

Molecular understanding of neutralizing antibody responses to SARS-CoV-2 could accelerate vaccine design and drug discovery. We analyzed 294 anti-SARS-CoV-2 antibodies and found that IGHV3-53 is the most frequently used IGHV gene for targeting the receptor-binding domain (RBD) of the spike protein. Cocrystal structures of two IGHV3-53 neutralizing antibodies with RBD, with or without Fab CR3022, at 2.33 to 3.20 A resolution revealed that the germline-encoded residues dominate recognition of the ACE2 binding site. This binding mode limits the IGHV3-53 antibodies to short CDR H3 loops, but accommodates lightchain diversity. These IGHV3-53 antibodies show minimal affinity maturation and high potency, which is promising for vaccine design. Knowledge of these structural motifs and binding mode should facilitate design of antigens that elicit this type of neutralizing response.

The ongoing COVID-19 pandemic of the severe acute respiratory syndrome coronavirus 2 (SARS-CoV-2) has caused enormous global health and socioeconomic damage and requires urgent development of an effective COVID-19 vaccine (1). While multiple vaccine candidates have entered clinical trials (2), the molecular features that contribute to an effective antibody response are not clear. Shared antibody responses to specific microbial pathogens have been found where the same genetic elements and modes of recognition are observed in multiple individuals against a given antigen. Such responses to microbial pathogens have been observed against influenza (3), dengue (4), malaria (5), and HIV (6). Characterization of their molecular interactions with cognate antigen can provide insight into how the immune repertoire is able to quickly respond to novel microbial pathogens, and facilitate rational vaccine design against these pathogens $(7,8)$.

The spike (S) protein is the major surface antigen of SARS$\mathrm{CoV}-2$. The $\mathrm{S}$ protein uses its receptor-binding domain (RBD) to engage the host receptor ACE2 for viral entry (9-12). RBDtargeting antibodies could then neutralize SARS-CoV-2 by blocking ACE2 binding. A number of antibodies that target the RBD of SARS-CoV-2 have now been discovered (13-28). We compiled a list of 294 SARS-CoV-2 RBD-targeting antibodies where information on IGHV gene usage is available (17-28) (table S1), and found that IGHV3-53 is the most frequently used IGHV gene among these antibodies (Fig. 1A), with $10 \%$ encoded by IGHV3-53, compared to $0.5 \%$ to $2.6 \%$ (mean of 1.8\%) in the repertoire of naïve healthy individuals
$(29,30)$. IGHV3-53 antibodies were found in 7 out of 12 studies and in 17 of 32 COVID-19 patient samples (17-28, 31). These IGHV3-53 antibodies not only had lower somatic mutation rates, but also were more potent compared to other germlines in the cohort investigated here (27) (fig. S1). The prevalence of IGHV3-53 in the antibody response in SARSCoV-2 patients has also been recognized in other antibody studies $(20,22,27)$.

To understand the molecular features that endow IGHV353 with favorable properties for RBD recognition, we determined crystal structures of two IGHV3-53 neutralizing antibodies, namely CC12.1 and CC12.3, in complex with the SARSCoV-2 RBD, and with a cross-reactive Fab CR3022 to SARSlike CoVs (17). $\mathrm{CC} 12.1$ and $\mathrm{CC} 12.3$ were previously isolated from a SARS-CoV-2-infected patient and shown to specific for the $\mathrm{RBD}(27) . \mathrm{CC} 12.1$ and $\mathrm{CC} 12.3\left(\mathrm{IC}_{50} \sim 20 \mathrm{ng} / \mathrm{ml}\right)$ were among the top four highly potent neutralizing antibodies in the panel of antibodies assayed against live replicating SARSCoV-2 virus and pseudovirus (27). Although $\mathrm{CC} 12.1$ and CC12.3 are both encoded by IGHV3-53, CC12.1 utilizes IGHJ6, IGKV1-9, and IGKJ3, whereas CC12.3 utilizes IGHJ4, IGKV320, and IGKJ1. This variation in IGHJ, IGKV, and IGKJ usage indicates that $\mathrm{CC} 12.1$ and $\mathrm{CC} 12.3$ belong to different clonotypes, but are encoded by a common IGHV3-53 germline gene (fig. S2). IgBlast analysis (32) shows that IGHV and IGKV of CC12.1 have acquired only four amino-acid changes (somatic mutations) during affinity maturation from the original germline antibody sequence (fig. S2, A and B). Similarly, 
$\mathrm{CC} 12.3$ is also minimally somatically mutated with three amino-acid changes in IGHV and a single amino-acid deletion in IGKV (fig. S2, A and C). The binding affinities $\left(\mathrm{K}_{\mathrm{d}}\right)$ of Fabs CC12.1 and CC12.3 to SARS-CoV-2 RBD are $17 \mathrm{nM}$ and 14 nM, respectively (fig. S3). Moreover, competition experiments suggest that CC12.1 and CC12.3 bind to a similar epitope, which overlaps with the ACE2 binding site, but not the CR3022 epitope (fig. S4).

We determined four complex crystal structures, CC12.1/RBD, $\quad \mathrm{CC} 12.3 / \mathrm{RBD}, \quad \mathrm{CC} 12.1 / \mathrm{RBD} / \mathrm{CR} 3022, \quad$ and $\mathrm{CC} 12.3 / \mathrm{RBD} / \mathrm{CR} 3022$ at resolutions of $3.20 \AA, 2.33 \AA, 2.70 \AA$, and $2.90 \AA$, respectively (table S2). CC12.1 and CC12.3 bind to the ACE2 binding site on SARS-CoV-2 RBD with an identical angle of approach (Fig. 1, B to D, and fig. S5). Interestingly, another IGHV3-53 antibody B38, whose structure was determined recently (23), binds to the ACE2 binding site on SARSCoV-2 RBD in a similar manner, but with a $\mathrm{K}_{\mathrm{d}}$ of $70.1 \mathrm{nM}$ (fig. S6). Similar to the ACE2 binding site (11), the epitopes of these antibodies can only be accessed when the RBD is in the "up" conformation (fig. S7). Among 17 ACE2 binding residues on RBD, 15 and 16 are within the epitopes of $\mathrm{CC} 12.1$ and $\mathrm{B} 38$, respectively, and 11 are in the epitope of $\mathrm{CC} 12.3$ (Fig. 2, A to D). Many of the epitope residues are not conserved between SARS-CoV-2 and SARS-CoV (Fig. 2E), explaining their lack of cross-reactivity (27). The buried surface area (BSA) from the heavy-chain interaction is quite similar in CC12.1 (723 $\left.\AA^{2}\right)$, CC12.3 $\left(698 \AA^{2}\right)$, and B38 (713 $\left.\AA^{2}\right)$. In contrast, the light-chain interaction is much smaller for CC12.3 (176 $\left.\AA^{2}\right)$ compared to CC12.1 (566 $\left.\AA^{2}\right)$ and B38 (495 $\left.\AA^{2}\right)$, consistent with different light-chain gene usage. While both $\mathrm{CC} 12.1$ and $\mathrm{B} 38$ use IGKV1-9, CC12.3 uses IGKV3-20, which suggests that IGHV353 can pair with different light chains to target the ACE2 binding site of the SARS-CoV-2 RBD. CC12.1 (56\% BSA from the heavy chain) binds the RBD with similar affinity to CC12.3 (80\% BSA from the heavy chain), but with slightly slower dissociation rate (fig. S3), which might be influenced by the different light chain and its greater contribution in CC12.1. Nevertheless, the light-chain identity seems not to be as critical as the heavy chain. In fact, among the RBD-targeting IGHV3-53 antibodies, nine different light chains are observed, although IGKV1-9 and IGKV3-20 are the most frequently found to date (fig. S8).

To understand why IGHV3-53 is elicited as a shared antibody response, the molecular interactions between the RBD and the heavy chains of $\mathrm{CC} 12.1, \mathrm{CC} 12.3$, and $\mathrm{B} 38$ were analyzed. The complementarity-determining regions (CDR) H1 and $\mathrm{H} 2$ of these antibodies interact extensively with the RBD mainly through specific hydrogen bonds (Fig. 3, A and B). Interestingly, all residues on $\mathrm{CDR} \mathrm{H} 1$ and $\mathrm{H} 2$ that hydrogen bond with the RBD are encoded by the germline IGHV3-53 (fig. S2 and table S3). These interactions are almost identical among $\mathrm{CC} 12.1, \mathrm{CC} 12.3$, and $\mathrm{B} 38$ with the only difference at $\mathrm{V}_{\mathrm{H}}$ residue 58. A somatic mutation $\mathrm{V}_{\mathrm{H}} \mathrm{Y} 58 \mathrm{~F}$ in $\mathrm{CC} 12.1$ and $\mathrm{CC} 12.3$, but not in B38 (Fig. 3, A to C, boxed residues, and fig. S9), results in similar van der Waals' interactions with only a loss of a single hydrogen bond from the hydroxyl of the germline Tyr in B38 to the RBD (Fig. 3C). Of note, none of these antibody interactions mimic ACE2 binding (Fig. 3D).

Our structural analysis reveals two key motifs in the IGHV3-53 germline sequence that are important for RBD binding, namely an NY motif at $\mathrm{V}_{\mathrm{H}}$ residues 32 and 33 in the CDR H1, and an SGGS motif at $V_{H}$ residues 53 to 56 in the CDR H2 (Fig. 3 and fig. S10). The side chain of $V_{H}$ N32 in the NY motif hydrogen bonds with the backbone carbonyl of $\mathrm{A} 475$ on the RBD, and this interaction is stabilized by an extensive network of hydrogen bonds with other antibody residues as well as a bound water molecule (Fig. 4A). $\mathrm{V}_{\mathrm{H}} \mathrm{N} 32$ also hydrogen bonds with $\mathrm{V}_{\mathrm{H}}$ R94, which in turn hydrogen bonds with N487 and Y489 on the RBD (Fig. 4A). These polar contacts not only enhance RBD-Fab interaction, but also stabilize the CDR conformations with the surrounding residues (framework). $\mathrm{V}_{\mathrm{H}} \mathrm{Y} 33$ in the NY motif inserts into a hydrophobic cage formed by RBD residues Y421, F456, L455 and the aliphatic component of K417 (Fig. 4B). A hydrogen bond between $V_{H}$ Y33 and the carbonyl oxygen of L455 on the RBD further strengthens the interaction. The second key motif SGGS in CDR H2 forms an extensive hydrogen bond network with the RBD (Fig. 4C), including four hydrogen bonds that involve the hydroxyl side chains of $\mathrm{V}_{\mathrm{H}} \mathrm{S} 53$ and $\mathrm{V}_{\mathrm{H}} \mathrm{S} 56$, and four water-mediated hydrogen bonds to the backbone carbonyl of $\mathrm{V}_{\mathrm{H}} \mathrm{G} 54$, the backbone amide of $\mathrm{V}_{\mathrm{H}} \mathrm{S} 56$, and the side chain of $V_{H}$ S56. Along with $V_{H}$ Y52, the SGGS motif takes part in a type I beta turn, with a positive $\Phi$-angle for $V_{\mathrm{H}} \mathrm{G} 55$ at the end of the turn. In addition, the $\mathrm{C} \alpha$ of $\mathrm{V}_{\mathrm{H}} \mathrm{G} 54$ is only $4 \AA$ away from the RBD, indicating that side chains of other amino acids would clash with the RBD if they were present at this position.

The NY and SGGS motifs, important for RBD binding, are both encoded in the IGHV3-53 germline gene. Besides IGHV3-53, only the closely related IGHV3-66 contains an NY motif in CDR H1 and an SGGS motif in CDR H2 (33). IGHV366 is also commonly observed $(19-22,24,26)$ in antibodies in SARS-CoV-2 patients (Fig. 1A), and is also well represented in the repertoire of healthy individuals $(0.3 \%$ to $1.7 \%$ of total antibodies) (29). Overall, our structural analysis has identified two germline-encoded binding motifs that enable IGHV3-53 to target the SARS-CoV-2 RBD with mutations apparently not required from affinity maturation.

While the binding mode of CDR $\mathrm{H} 1$ and $\mathrm{H} 2$ to $\mathrm{RBD}$ is highly similar among CC12.1, CC12.3, and B38, CDR H3 interaction with the RBD varies (Fig. 3, A to C) due to differences in the CDR H3 sequences and conformations (fig. S1 and Fig. 4D). For example, while CDR $\mathrm{H} 3$ of $\mathrm{CC} 12.1$ interacts with $\mathrm{RBD}$ Y453 through a hydrogen bond, CDR H3 of $\mathrm{CC} 12.3$ and B38 
do not form such a hydrogen bond (Fig. 3, A to C). Similarly, due to the difference in light-chain gene usage, light-chain interactions with the RBD can vary substantially in IGHV353 antibodies (fig. S11). Overall, our structural analysis demonstrates that IGHV3-53 provides a versatile framework to target the ACE2 binding site in SARS-CoV-2 RBD.

An interesting feature of $\mathrm{CC} 12.1$ and $\mathrm{CC} 12.3$ is their relatively short CDR H3. While the CDR H3 sequences of CC12.1 and $\mathrm{CC} 12.3$ differ, both are nine amino acids in length (Kabat numbering) (34). Antibody B38 has an even shorter CDR H3 of seven residues (23). The average CDR H3 length for human antibodies is around 13 (35), although very long CDR H3s (up to 30 residues) are found in many broadly neutralizing antibodies to HIV-1 (36). Longer CDR H3 's cannot be accommodated in these IGHV3-53 antibodies since their epitopes are relatively flat with only a small large pocket to insert their CDR H3 loop (Fig. 4D). A similar conclusion was reached in another recent study, which also reported that SARS-CoV-2 RBD-targeting antibodies encoded by IGHV3-53 or IGHV3-66 tend to have a short CDR H3 $(28,37)$. Consistently, among the RBD-targeting antibodies currently reported (17-28), IGHV3-53 antibodies have a significantly shorter CDR H3 compared to those encoded by other IGHV genes ( $\mathrm{p}$-value $=$ 6e-8, Mann-Whitney U test) (fig. S12), and shorter than IGHV3-53-encoded antibodies in the naive human antibody repertoire (30). Thus, a short CDR H3 length is one of the molecular features of the IGHV3-53-encoded antibody response to SARS-CoV-2 RBD, reminiscent of a below average 5-residue CDR L3 in IGHV1-2 antibodies to the receptor binding site in HIV-1 Env gp120 (38). Nevertheless, a small subset of these IGHV3-53 antibodies have longer CDR H3s that warrant further investigation of their binding mode (fig. S12).

Besides IGHV3-53, several other IGHV genes such as IGHV12, IGHV3-9, and IGHV3-30 are also more frequently observed than other germlines in SARS-CoV-2 RBD-targeting antibodies (Fig. 1A). The molecular mechanisms of these IGHV responses to SARS-CoV-2 need characterization, as well as whether other germline gene segments, including IGHD and the light chain contribute in recurring motifs to the SARS-CoV-2 antibody response. The characterization of these IGHV3-53 antibodies to SARS-CoV-2 is a promising starting point for rational vaccine design (39), given that limited to no affinity maturation is required to achieve a highly potent neutralizing antibody response to the RBD. As IGHV3-53 is found at a reasonable frequency in healthy individuals $(29,30)$, this particular antibody response could be commonly elicited during vaccination (40).

\section{REFERENCES AND NOTES}

1. S. M. Kissler, C. Tedijanto, E. Goldstein, Y. H. Grad, M. Lipsitch, Projecting the transmission dynamics of SARS-CoV-2 through the postpandemic period. Science 368, 860-868 (2020).

2. N. Lurie, M. Saville, R. Hatchett, J. Halton, Developing COVID-19 vaccines at pandemic speed. N. Engl. J. Med. 382, 1969-1973 (2020).

doi:10.1056/NEJMp2005630 Medline

3. S. F. Andrews, A. B. McDermott, Shaping a universally broad antibody response to influenza amidst a variable immunoglobulin landscape. Curr. Opin. Immunol. 53 , 96-101 (2018). doi:10.1016/i.coi.2018.04.009 Medline

4. P. Parameswaran, Y. Liu, K. M. Roskin, K. K. L. Jackson, V. P. Dixit, J.-Y. Lee, K. L. Artiles, S. Zompi, M. J. Vargas, B. B. Simen, B. Hanczaruk, K. R. McGowan, M. A. Tariq, N. Pourmand, D. Koller, A. Balmaseda, S. D. Boyd, E. Harris, A. Z. Fire, Convergent antibody signatures in human dengue. Cell Host Microbe 13, 691-700 (2013). doi:10.1016/i.chom.2013.05.008 Medline

5. K. Pieper, J. Tan, L. Piccoli, M. Foglierini, S. Barbieri, Y. Chen, C. Silacci-Fregni, T. Wolf, D. Jarrossay, M. Anderle, A. Abdi, F. M. Ndungu, O. K. Doumbo, B. Traore, T. M. Tran, S. Jongo, I. Zenklusen, P. D. Crompton, C. Daubenberger, P. C. Bull, F. Sallusto, A. Lanzavecchia, Public antibodies to malaria antigens generated by two LAIR1 insertion modalities. Nature 548, 597-601(2017). doi:10.1038/nature23670 Medline

6. I. Setliff, W. J. McDonnell, N. Raju, R. G. Bombardi, A. A. Murji, C. Scheepers, R. Ziki, C. Mynhardt, B. E. Shepherd, A. A. Mamchak, N. Garrett, S. A. Karim, S. A. Mallal, J. E. Crowe Jr., L. Morris, I. S. Georgiev, Multi-donor longitudinal antibody repertoire sequencing reveals the existence of public antibody clonotypes in HIV1 infection. Cell Host Microbe 23, 845-854.e6 (2018). doi:10.1016/i.chom.2018.05.001 Medline

7. N. C. Wu, I. A. Wilson, Structural insights into the design of novel anti-influenza therapies. Nat. Struct. Mol. Biol. 25, 115-121 (2018). doi:10.1038/s41594-0180025-9 Medline

8. A. Lanzavecchia, A. Frühwirth, L. Perez, D. Corti, Antibody-guided vaccine design: Identification of protective epitopes. Curr. Opin. Immunol. 41, 62-67 (2016). doi:10.1016/i.coi.2016.06.001 Medline

9. P. Zhou, X.-L. Yang, X.-G. Wang, B. Hu, L. Zhang, W. Zhang, H.-R. Si, Y. Zhu, B. Li, C.L. Huang, H.-D. Chen, J. Chen, Y. Luo, H. Guo, R.-D. Jiang, M.-Q. Liu, Y. Chen, X.-R. Shen, X. Wang, X.-S. Zheng, K. Zhao, Q.-J. Chen, F. Deng, L.-L. Liu, B. Yan, F.-X. Zhan, Y.-Y. Wang, G.-F. Xiao, Z.-L. Shi, A pneumonia outbreak associated with a new coronavirus of probable bat origin. Nature 579, 270-273 (2020). doi:10.1038/s41586-020-2012-7 Medline

10. M. Letko, A. Marzi, V. Munster, Functional assessment of cell entry and receptor usage for SARS-CoV-2 and other lineage B betacoronaviruses. Nat. Microbiol. 5 , 562-569 (2020). doi:10.1038/s41564-020-0688-y Medline

11. R. Yan, Y. Zhang, Y. Li, L. Xia, Y. Guo, Q. Zhou, Structural basis for the recognition of SARS-CoV-2 by full-length human ACE2. Science 367, 1444-1448 (2020). doi:10.1126/science.abb2762 Medline

12. J. Lan, J. Ge, J. Yu, S. Shan, H. Zhou, S. Fan, Q. Zhang, X. Shi, Q. Wang, L. Zhang, X. Wang, Structure of the SARS-CoV-2 spike receptor-binding domain bound to the ACE2 receptor. Nature 581, 215-220 (2020). doi:10.1038/s41586-020-2180-5 Medline

13. W. Li, A. Drelich, D. R. Martinez, L. Gralinski, C. Chen, Z. Sun, X. Liu, D. Zhelev, L. Zhang, E. C. Peterson, A. Conard, J. W. Mellors, C. T. Tseng, R. S. Baric, D. S. Dimitrov, Potent neutralization of SARS-CoV-2 in vitro and in an animal model by a human monoclonal antibody. bioRxiv 2020.05.13.093088 [Preprint] (2 June 2020); https://doi.org/10.1101/2020.05.13.093088.

14. E. Andreano, E. Andreano, E. Nicastri, I. Paciello, P. Pileri, N. Manganaro, G. Piccini, A. Manenti, E. Pantano, A. Kabanova, M. Troisi, F. Vacca, D. Cardamone, C. De Santi, C. Agrati, M. R. Capobianchi, C. Castilletti, A. Emiliozzi, M. Fabbiani, F. Montagnani, E. Montomoli, C. Sala, G. Ippolito, R. Rappuoli, Identification of neutralizing human monoclonal antibodies from Italian Covid-19 convalescent patients. bioRxiv 2020.05.05.078154 [Preprint] (9 May 2020); https://doi.org/10.1101/2020.05.05.078154.

15. S. J. Zost, P. Gilchuk, R. E. Chen, J. B. Case, J. X. Reidy, A. Trivette, R. S. Nargi, R. E. Sutton, N. Suryadevara, E. C. Chen, E. Binshtein, S. Shrihari, M. Ostrowski, H. Y. Chu, J. E. Didier, K. W. MacRenaris, T. Jones, S. Day, L. Myers, F. E. Lee, D. C. Nguyen, I. Sanz, D. R. Martinez, R. S. Baric, L. B. Thackray, M. S. Diamond, R. H. Carnahan, J. E. Crowe, Rapid isolation and profiling of a diverse panel of human monoclonal antibodies targeting the SARS-CoV-2 spike protein. bioRxiv 2020.05.12.091462 [Preprint] (13 May 2020): https://doi.org/10.1101/2020.05.12.091462.

16. A. Z. Wec, D. Wrapp, A. S. Herbert, D. P. Maurer, D. Haslwanter, M. Sakharkar, R. K. Jangra, M. E. Dieterle, A. Lilov, D. Huang, L. V. Tse, N. V. Johnson, C.-L. Hsieh, N. Wang, J. H. Nett, E. Champney, I. Burnina, M. Brown, S. Lin, M. Sinclair, C. Johnson, S. Pudi, R. Bortz 3rd, A. S. Wirchnianski, E. Laudermilch, C. Florez, J. M. 
Fels, C. M. O'Brien, B. S. Graham, D. Nemazee, D. R. Burton, R. S. Baric, J. E. Voss, K. Chandran, J. M. Dye, J. S. McLellan, L. M. Walker, Broad neutralization of SARSrelated viruses by human monoclonal antibodies. Science eabc7424 (2020). doi:10.1126/science.abc7424 Medline

17. M. Yuan, N. C. Wu, X. Zhu, C. D. Lee, R. T. Y. So, H. Lv, C. K. P. Mok, I. A. Wilson, A highly conserved cryptic epitope in the receptor binding domains of SARS-CoV-2 and SARS-CoV. Science 368, 630-633 (2020). doi:10.1126/science.abb7269 Medline

18. D. Pinto, Y.-J. Park, M. Beltramello, A. C. Walls, M. A. Tortorici, S. Bianchi, S. Jaconi, K. Culap, F. Zatta, A. De Marco, A. Peter, B. Guarino, R. Spreafico, E. Cameroni, J. B. Case, R. E. Chen, C. Havenar-Daughton, G. Snell, A. Telenti, H. W. Virgin, A. Lanzavecchia, M. S. Diamond, K. Fink, D. Veesler, D. Corti, Cross-neutralization of SARS-CoV-2 by a human monoclonal SARS-CoV antibody. Nature 583, 290-295 (2020). doi:10.1038/s41586-020-2349-y Medline

19. B. Ju, Q. Zhang, X. Ge, R. Wang, J. Yu, S. Shan, B. Zhou, S. Song, X. Tang, J. Yu, J. Ge, J. Lan, J. Yuan, H. Wang, J. Zhao, S. Zhang, Y. Wang, X. Shi, L. Liu, X. Wang, Z. Zhang, L. Zhang, Potent human neutralizing antibodies elicited by SARS-CoV-2 infection. bioRxiv 2020.03.21.990770 [Preprint] (26 March 2020): https://doi.org/10.1101/2020.03.21.990770.

20. Y. Cao, B. Su, X. Guo, W. Sun, Y. Deng, L. Bao, Q. Zhu, X. Zhang, Y. Zheng, C. Geng, X. Chai, R. He, X. Li, Q. Lv, H. Zhu, W. Deng, Y. Xu, Y. Wang, L. Qiao, Y. Tan, L. Song, G. Wang, X. Du, N. Gao, J. Liu, J. Xiao, X. D. Su, Z. Du, Y. Feng, C. Qin, C. Qin, R. Jin, X. S. Xie, Potent neutralizing antibodies against SARS-CoV-2 identified by highthroughput single-cell sequencing of convalescent patients' B cells. Cell 10.1016/j.cell.2020.05.025 (2020). doi:10.1016/i.cell.2020.05.025 Medline

21. P. J. M. Brouwer, T. G. Caniels, K. van der Straten, J. L. Snitselaar, Y. Aldon, S. Bangaru, J. L. Torres, N. M. A. Okba, M. Claireaux, G. Kerster, A. E. H. Bentlage, M. M. van Haaren, D. Guerra, J. A. Burger, E. E. Schermer, K. D. Verheul, N. van der Velde, A. van der Kooi, J. van Schooten, M. J. van Breemen, T. P. L. Biil, K. Sliepen, A. Aartse, R. Derking, I. Bontjer, N. A. Kootstra, W. J. Wiersinga, G. Vidarsson, B. L. Haagmans, A. B. Ward, G. J. de Bree, R. W. Sanders, M. J. van Gils, Potent neutralizing antibodies from COVID-19 patients define multiple targets of vulnerability. Science eabc5902 (2020). doi:10.1126/science.abc5902 Medline

22. D. F. Robbiani, C. Gaebler, F. Muecksch, J. C. C. Lorenzi, Z. Wang, A. Cho, M. Agudelo, C. O. Barnes, A. Gazumyan, S. Finkin, T. Hägglöf, T. Y. Oliveira, C. Viant, A. Hurley, H.-H. Hoffmann, K. G. Millard, R. G. Kost, M. Cipolla, K. Gordon, F. Bianchini, S. T. Chen, V. Ramos, R. Patel, J. Dizon, I. Shimeliovich, P. Mendoza, H. Hartweger, L. Nogueira, M. Pack, J. Horowitz, F. Schmidt, Y. Weisblum, E. Michailidis, A. W. Ashbrook, E. Waltari, J. E. Pak, K. E. Huey-Tubman, N. Koranda, P. R. Hoffman, A. P. West Jr., C. M. Rice, T. Hatziioannou, P. J. Bjorkman, P. D. Bieniasz, M. Caskey, M. C. Nussenzweig, Convergent antibody responses to SARS-CoV-2 in convalescent individuals. Nature 10.1038/s41586-020-2456-9 (2020). doi:10.1038/s41586-020-2456-9 Medline

23. Y. Wu, F. Wang, C. Shen, W. Peng, D. Li, C. Zhao, Z. Li, S. Li, Y. Bi, Y. Yang, Y. Gong, H. Xiao, Z. Fan, S. Tan, G. Wu, W. Tan, X. Lu, C. Fan, Q. Wang, Y. Liu, C. Zhang, J. Qi, G. F. Gao, F. Gao, L. Liu, A noncompeting pair of human neutralizing antibodies block COVID-19 virus binding to its receptor ACE2. Science 368, 1274-1278 (2020). doi:10.1126/science.abc2241 Medline

24. X. Chi, R. Yan, J. Zhang, G. Zhang, Y. Zhang, M. Hao, Z. Zhang, P. Fan, Y. Dong, Y. Yang, Z. Chen, Y. Guo, J. Zhang, Y. Li, X. Song, Y. Chen, L. Xia, L. Fu, L. Hou, J. Xu, C. Yu, J. Li, Q. Zhou, W. Chen, A potent neutralizing human antibody reveals the Nterminal domain of the Spike protein of SARS-CoV-2 as a site of vulnerability. bioRxiv 2020.05.08.083964 [Preprint] (8 May 2020); https://doi.org/10.1101/2020.05.08.083964.

25. E. Seydoux, L. J. Homad, A. J. MacCamy, K. R. Parks, N. K. Hurlburt, M. F. Jennewein, N. R. Akins, A. B. Stuart, Y.-H. Wan, J. Feng, R. E. Whaley, S. Singh, M. Boeckh, K. W. Cohen, M. J. McElrath, J. A. Englund, H. Y. Chu, M. Pancera, A. T. McGuire, L. Stamatatos, Analysis of a SARS-CoV-2-infected individual reveals development of potent neutralizing antibodies with limited somatic mutation. Immunity 10.1016/j.immuni.2020.06.001(2020). doi:10.1016/i.immuni.2020.06.001 Medline

26. R. Shi, C. Shan, X. Duan, Z. Chen, P. Liu, J. Song, T. Song, X. Bi, C. Han, L. Wu, G. Gao, X. Hu, Y. Zhang, Z. Tong, W. Huang, W. J. Liu, G. Wu, B. Zhang, L. Wang, J. Qi, H. Feng, F. S. Wang, Q. Wang, G. F. Gao, Z. Yuan, J. Yan, A human neutralizing antibody targets the receptor binding site of SARS-CoV-2. Nature 10.1038/s41586-020-2381-y (2020). doi:10.1038/s41586-020-2381-y Medline

27. T. F. Rogers, F. Zhao, D. Huang, N. Beutler, A. Burns, W. T. He, O. Limbo, C. Smith, G. Song, J. Woehl, L. Yang, R. K. Abbott, S. Callaghan, E. Garcia, J. Hurtado, M. Parren, L. Peng, S. Ramirez, J. Ricketts, M. J. Ricciardi, S. A. Rawlings, N. C. Wu, M. Yuan, D. M. Smith, D. Nemazee, J. R. Teijaro, J. E. Voss, I. A. Wilson, R. Andrabi, B. Briney, E. Landais, D. Sok, J. G. Jardine, D. R. Burton, Isolation of potent SARSCoV-2 neutralizing antibodies and protection from disease in a small animal model. Science eabc7520 (2020). doi:10.1126/science.abc7520 Medline

28. C. O. Barnes, A. P. West Jr., K. E. Huey-Tubman, M. A. G. Hoffmann, N. G. Sharaf, P. R. Hoffman, N. Koranda, H. B. Gristick, C. Gaebler, F. Muecksch, J. C. Cetrulo Lorenzi, S. Finkin, T. Hägglöf, A. Hurley, K. G. Millard, Y. Weisblum, F. Schmidt, T. Hatziioannou, P. D. Bieniasz, M. Caskey, D. F. Robbiani, M. C. Nussenzweig, P. J. Bjorkman, Structures of human antibodies bound to SARS-CoV-2 spike reveal common epitopes and recurrent features of antibodies. Cell 10.1101/2020.05.28.121533 (2020). doi:10.1016/i.cell.2020.06.025 Medline

29. S. D. Boyd, B. A. Gaëta, K. J. Jackson, A. Z. Fire, E. L. Marshall, J. D. Merker, J. M. Maniar, L. N. Zhang, B. Sahaf, C. D. Jones, B. B. Simen, B. Hanczaruk, K. D. Nguyen, K. C. Nadeau, M. Egholm, D. B. Miklos, J. L. Zehnder, A. M. Collins, Individual variation in the germline $\mathrm{g}$ gene repertoire inferred from variable region gene rearrangements. J. Immunol. 184, 6986-6992 (2010). doi:10.4049/iimmunol.1000445 Medline

30. B. Briney, A. Inderbitzin, C. Joyce, D. R. Burton, Commonality despite exceptional diversity in the baseline human antibody repertoire. Nature 566, 393-397 (2019). doi:10.1038/s41586-019-0879-y Medline

31. The highly related IGHV3-66-encoded RBD-targeting antibodies are also frequently found and reported in 5 out of 12 studies and in 11 of 32 patients (1728).

32. J. Ye, N. Ma, T. L. Madden, J. M. Ostell, IgBLAST: An immunoglobulin variable domain sequence analysis tool. Nucleic Acids Res. 41. W34-40 (2013). doi:10.1093/nar/gkt382 Medline

33. The amino-acid sequences of IGHV3-53 and IGHV3-66 germline genes only differ by one amino acid at residue 12 . Specifically, IGHV3-53 contains Ile12, whereas IGHV3-66 contains Val12.

34. CDRH3 lengths with Kabat numbering are two amino acids shorter than those with IMGT numbering.

35. M. Zemlin, M. Klinger, J. Link, C. Zemlin, K. Bauer, J. A. Engler, H. W. Schroeder Jr., P. M. Kirkham, Expressed murine and human CDR-H3 intervals of equal length exhibit distinct repertoires that differ in their amino acid composition and predicted range of structures. J. Mol. Biol. 334, 733-749 (2003). doi:10.1016/i.jmb.2003.10.007 Medline

36. L. Yu, Y. Guan, Immunologic basis for long HCDR3s in broadly neutralizing antibodies against HIV-1. Front. Immunol. 5, 250 (2014). doi:10.3389/fimmu.2014.00250 Medline

37. IGHV3-53 and IGHV3-66 antibodies in general have slightly shorter than average CDR H3s (by around one residue), and also appear to have a few much shorter CDR H3s ( $<10$ amino acids) than average in the baseline antibody repertoire (30).

38. J. G. Jardine, T. Ota, D. Sok, M. Pauthner, D. W. Kulp, O. Kalyuzhniy, P. D. Skog, T. C. Thinnes, D. Bhullar, B. Briney, S. Menis, M. Jones, M. Kubitz, S. Spencer, Y Adachi, D. R. Burton, W. R. Schief, D. Nemazee, HIV-1 VACCINES. Priming a broadly neutralizing antibody response to HIV-1 using a germline-targeting immunogen. Science 349, 156-161 (2015). doi:10.1126/science.aac5894 Medline

39. D. R. Burton, L. M. Walker, Rational vaccine design in the time of COVID-19. Cell Host Microbe 27, 695-698 (2020). doi:10.1016/i.chom.2020.04.022 Medline

40. R. K. Abbott, S. Crotty, Factors in B cell competition and immunodominance. Immunol. Rev. 10.1111/imr.12861 (2020). doi:10.1111/imr.12861 Medline

41. E. Krissinel, K. Henrick, Inference of macromolecular assemblies from crystalline state. J. Mol. Biol. 372, 774-797 (2007). doi:10.1016/i.jmb.2007.05.022 Medline

42. D. C. Ekiert, R. H. E. Friesen, G. Bhabha, T. Kwaks, M. Jongeneelen, W. Yu, C. Ophorst, F. Cox, H. J. W. M. Korse, B. Brandenburg, R. Vogels, J. P. J. Brakenhoff, R. Kompier, M. H. Koldijk, L. A. H. M. Cornelissen, L. L. M. Poon, M. Peiris, W. Koudstaal, I. A. Wilson, J. Goudsmit, A highly conserved neutralizing epitope on group 2 influenza A viruses. Science 333, 843-850 (2011) doi:10.1126/science.1204839 Medline

43. Z. Otwinowski, W. Minor, Processing of X-ray diffraction data collected in oscillation mode. Methods Enzymol. 276, 307-326 (1997). doi:10.1016/S0076- 
6879(97)76066-X

44. A. J. McCoy, R. W. Grosse-Kunstleve, P. D. Adams, M. D. Winn, L. C. Storoni, R. J. Read, Phaser crystallographic software. J. Appl. Cryst. 40, 658-674 (2007). doi:10.1107/S0021889807021206 Medline

45. J. Huo, Y. Zhao, J. Ren, D. Zhou, H. M. E. Duyvesteyn, H. M. Ginn, L. Carrique, T. Malinauskas, R. R. Ruza, P. N. M. Shah, T. K. Tan, P. Rijal, N. Coombes, K. R. Bewley, J. A. Tree, J. Radecke, N. G. Paterson, P. Supasa, J. Mongkolsapaya, G. R. Screaton, M. Carroll, A. Townsend, E. E. Fry, R. J. Owens, D. I. Stuart, Neutralization of SARS-CoV-2 by destruction of the prefusion Spike. bioRxiv 2020.05.05.079202 [Preprint] (6 May 2020); https://doi.org/10.1101/2020.05.05.079202.

46. X. Chen, K. Hnida, M. A. Graewert, J. T. Andersen, R. Iversen, A. Tuukkanen, D. Svergun, L. M. Sollid, Structural basis for antigen recognition by transglutaminase 2-specific autoantibodies in celiac disease. J. Biol. Chem. 290, 21365-21375 (2015). doi:10.1074/ibc.M115.669895 Medline

47. P. Emsley, B. Lohkamp, W. G. Scott, K. Cowtan, Features and development of Coot Acta Crystallogr. D Biol. Crystallogr. 66, 486-501(2010). doi:10.1107/S0907444910007493 Medline

48. P. D. Adams, P. V. Afonine, G. Bunkóczi, V. B. Chen, I. W. Davis, N. Echols, J. J. Headd, L.-W. Hung, G. J. Kapral, R. W. Grosse-Kunstleve, A. J. McCoy, N. W. Moriarty, R. Oeffner, R. J. Read, D. C. Richardson, J. S. Richardson, T. C. Terwilliger, P. H. Zwart, PHENIX: A comprehensive Python-based system for macromolecular structure solution. Acta Crystallogr. D Biol. Crystallogr. 66, 213221 (2010). doi:10.1107/S0907444909052925 Medline

49. N. C. Wu, G. Grande, H. L. Turner, A. B. Ward, J. Xie, R. A. Lerner, I. A. Wilson, In vitro evolution of an influenza broadly neutralizing antibody is modulated by hemagglutinin receptor specificity. Nat. Commun. 8, 15371(2017). doi:10.1038/ncomms15371 Medline

50. D. Wrapp, N. Wang, K. S. Corbett, J. A. Goldsmith, C.-L. Hsieh, O. Abiona, B. S. Graham, J. S. McLellan, Cryo-EM structure of the 2019-nCoV spike in the prefusion conformation. Science 367, 1260-1263 (2020).

doi:10.1126/science.abb2507 Medline

\section{ACKNOWLEDGMENTS}

We thank Robyn Stanfield for assistance in data collection and Bryan Briney for naïve antibody germline analysis. We are grateful to the staff of Stanford Synchrotron Radiation Laboratory (SSRL) Beamline 12-1 for assistance. Funding: This work was supported by NIH K99 Al139445 (N.C.W.), the Bill and Melinda Gates Foundation OPP1170236 (I.A.W. and D.R.B.), NIH NIAID CHAVD (UM1 AI44462 to I.A.W., D.S. and D.R.B.), and the IAVI Neutralizing Antibody Center. Use of the SSRL, SLAC National Accelerator Laboratory, is supported by the U.S. Department of Energy, Office of Science, Office of Basic Energy Sciences under Contract No. DE-AC02-76SF00515. The SSRL Structural Molecular Biology Program is supported by the DOE Office of Biological and Environmental Research, and by the National Institutes of Health, National Institute of General Medical Sciences (including P41GM103393). Author contributions: M.Y., H.L., N.C.W., F.Z., D.H., T.F.R., E.L., D.S, J.G.J., D.R.B. and I.A.W. conceived and designed the study. F.Z., D.H., T.F.R., E.L., D.S., J.G.J., and D.R.B. isolated the antibodies and provided clones and sequences. M.Y., H.L., N.C.W., C.C.D.L., W.Y. and Y.H. expressed and purified the proteins. M.Y. and C.C.D.L. performed biolayer interferometry binding assays. M.Y., H.L., N.C.W., X.Z. and H.T. performed the crystallization and X-ray data collection. M.Y. and X.Z. determined and refined the X-ray structures. M.Y., H.L., N.C.W., C.C.D.L. and X.Z. analyzed the data. M.Y., H.L., N.C.W. and I.A.W. wrote the paper and all authors reviewed and/or edited the paper. Competing interests: D.R.B., D.H., J.G.J., E.L., T.F.R., D.S. and F.Z. are listed as inventors on pending patent applications describing the SARS-CoV-2 antibodies originally published in T. F. Rogers et al., Science 10.1126/science.abc7520 (2020). Data and materials availability: X-ray coordinates and structure factors are deposited in the RCSB Protein Data Bank under IDs $6 \times C 2,6 \times C 3,6 \times C 4$, and 6XC7. Antibody plasmids are available from Dennis Burton under an MTA from The Scripps Research Institute. Other materials are available from I.A.W. on request. This work is licensed under a Creative Commons Attribution 4.0 International (CC BY 4.0) license, which permits unrestricted use, distribution, and reproduction in any medium, provided the original work is properly cited. To view a copy of this license, visit https://creativecommons.org/licenses/by/4.0/. This license does not apply to figures/photos/artwork or other content included in the article that is credited to a third party; obtain authorization from the rights holder before using such material.

\section{SUPPLEMENTARY MATERIALS}

science.sciencemag.org/cgi/content/full/science.abd2321/DC1

Materials and Methods

Figs. S1 to S12

Tables S1 to S3

References (42-50)

MDAR Reproducibility Checklist

9 June 2020; accepted 7 July 2020

Published online 13 July 2020

10.1126/science.abd2321 
A
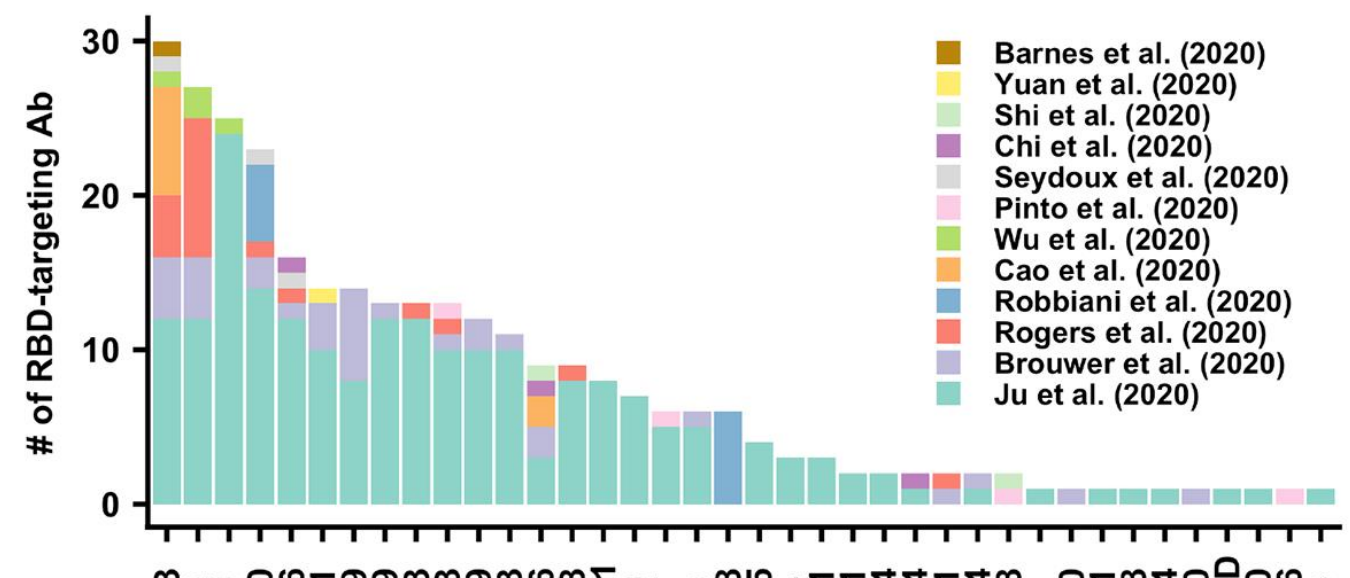

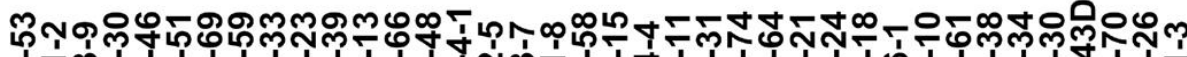

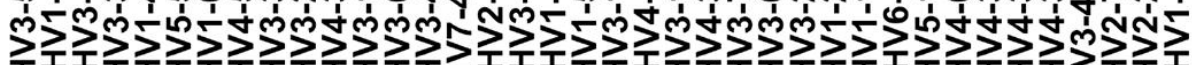

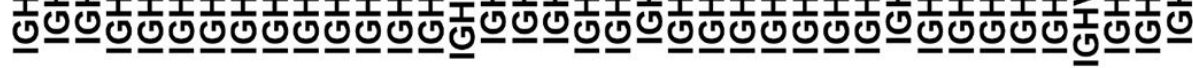
IGHV gene

B

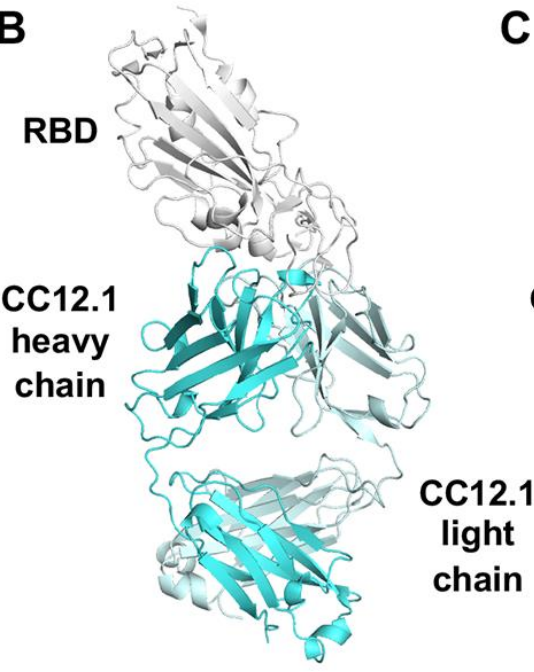

C

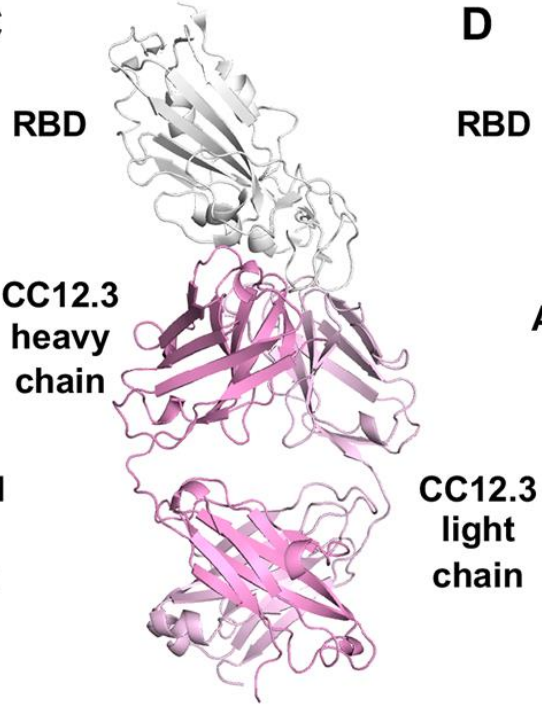

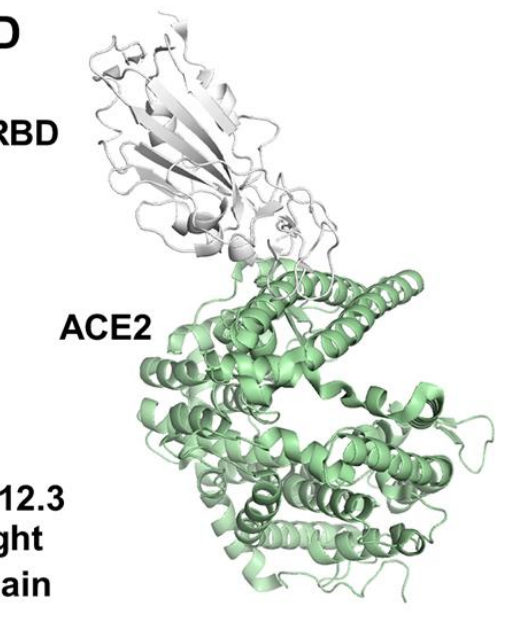

Fig. 1. Structures of two IGHV3-53 antibodies. (A) The distribution of IGHV gene usage is shown for a total of 294 RBD-targeting antibodies (17-28). (B and C) Crystal structures of (B) CC12.1 in complex with SARS-CoV-2 RBD, (C) CC12.3 with SARS-CoV-2 RBD, and (D) human ACE2 with SARS-CoV-2 RBD (PDB 6MOJ) (12). 
A

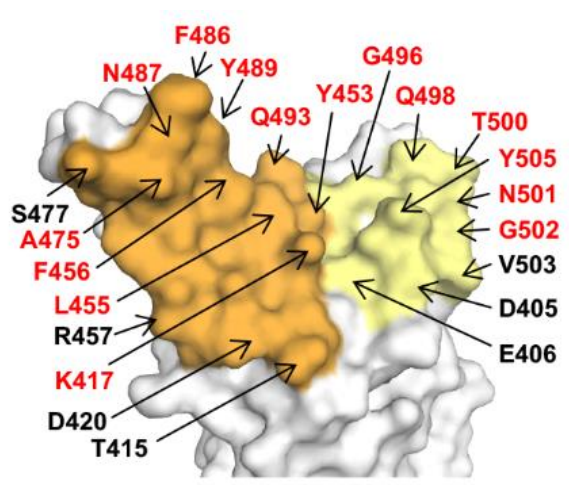

B

CC12.1
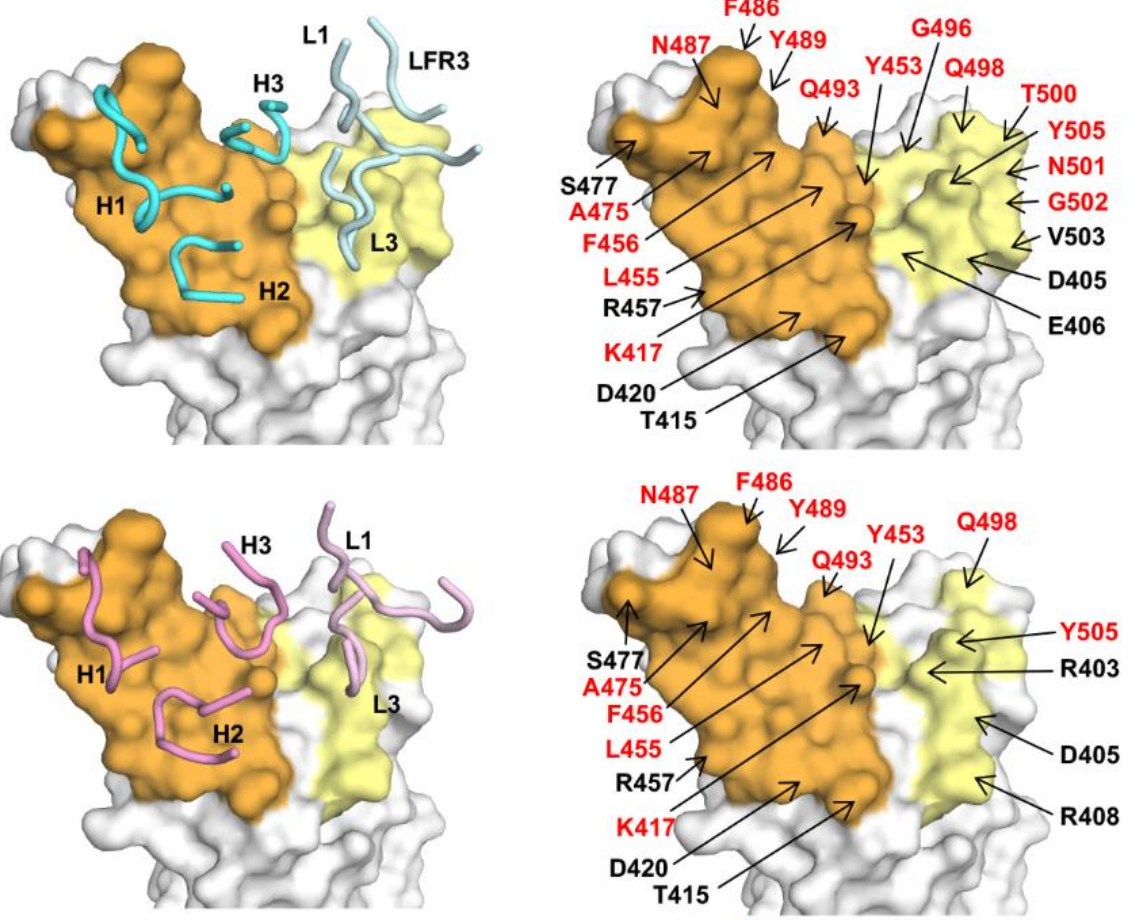

C

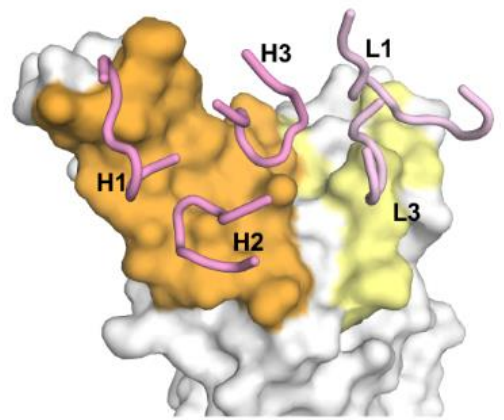

CC12.3
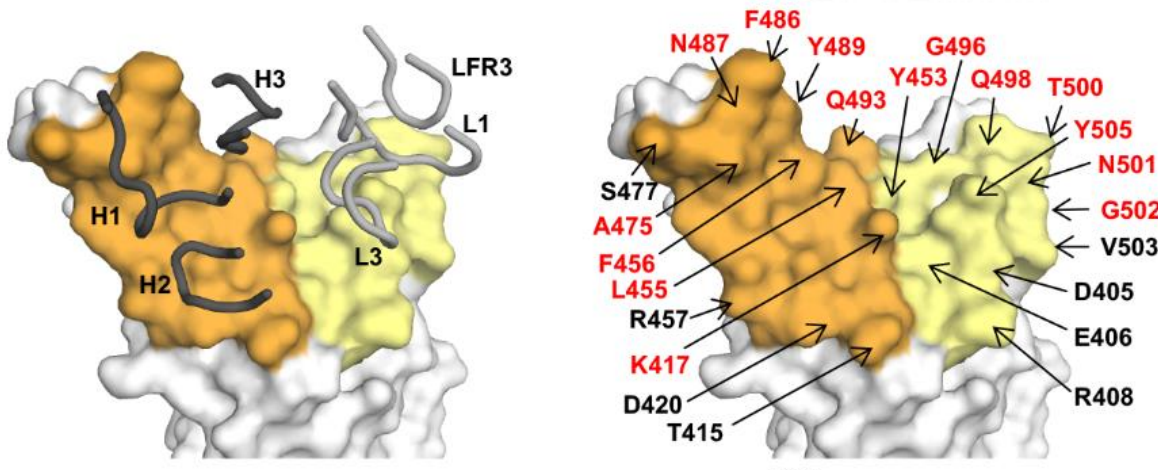

D

B38
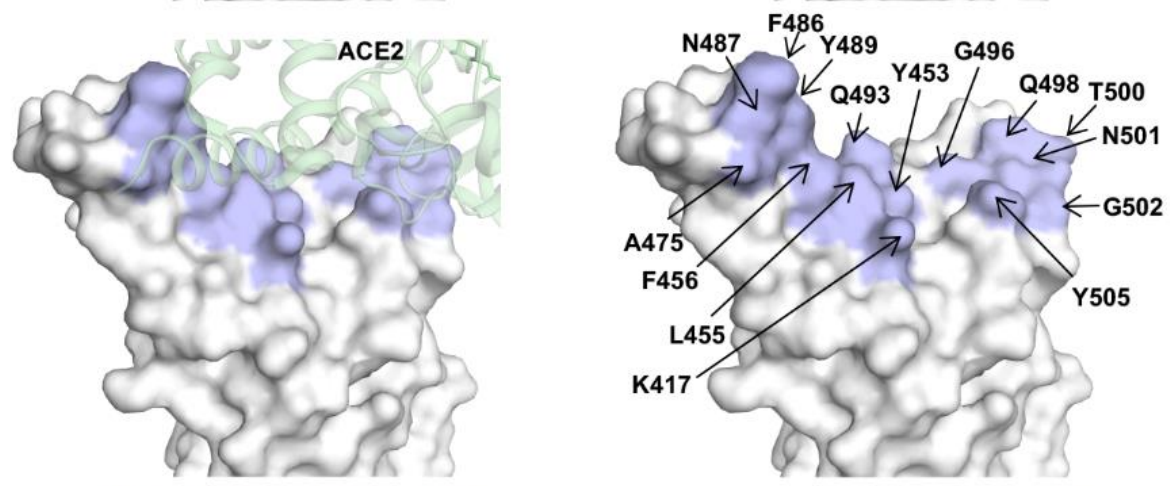

E
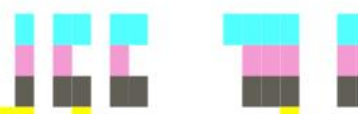

SARS-COV-2 RBD SARS-COV RBD

IRGDEVROI APGQTGKIADYNYKLPDDFTGCVIAWNSNNLDSKVGGNYNYLYR 454 389 VKGDDVRQIAPGQTGVIADYNYKLPDDFMGCVLAWNTRNIDATSTGNHNYKYR 441

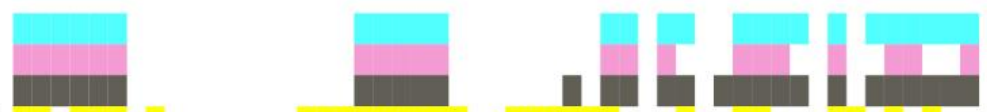

SARS-COV-2 RBD 455 LFRKSNLKPFERDISTEIYQAGSTPCNGVEGFNCYFPLQSYGFQPTNGVGYQP 507 SARS-COV RBD 442 YLRHGKLRPFERDISNVPFSPDGKPCTP-PALNCYWPLNDYGFYTTTGIGYQP 493 $Y L R$

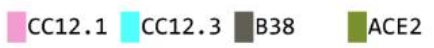


Fig. 2. Epitopes of IGHV35-3 antibodies. (A to C) Epitopes of (A) CC12.1, (B) CC12.3, and (C) B38 (PDB 7BZ5) (23). Epitope residues contacting the heavy chain are in orange and the light chain are in yellow. On the left panels, CDR loops are labeled. On the right panels, epitope residues are labeled. For clarity, only representative epitope residues are labeled. Epitope residues that are also involved in ACE2 binding are in red. (D) ACE2-binding residues are shown in blue. On the left panel, ACE2 is shown in green within a semitransparent surface representation. On the right panel, ACE2-binding residues are labeled. A total of 17 residues are used for ACE2 binding (12), but only 15 are labeled here since the other two are at the back of the structure in this view and do not interact with the antibodies here. (E) Epitope residues for CC12.1, CC12.3, and B38 were identified by PISA (41) and annotated on the SARS-CoV-2 RBD sequence, which is aligned to the SARS-CoV RBD sequence with non-conserved residues highlighted. The 17 ACE2-binding residues were as described previously (12). 
CDR H1
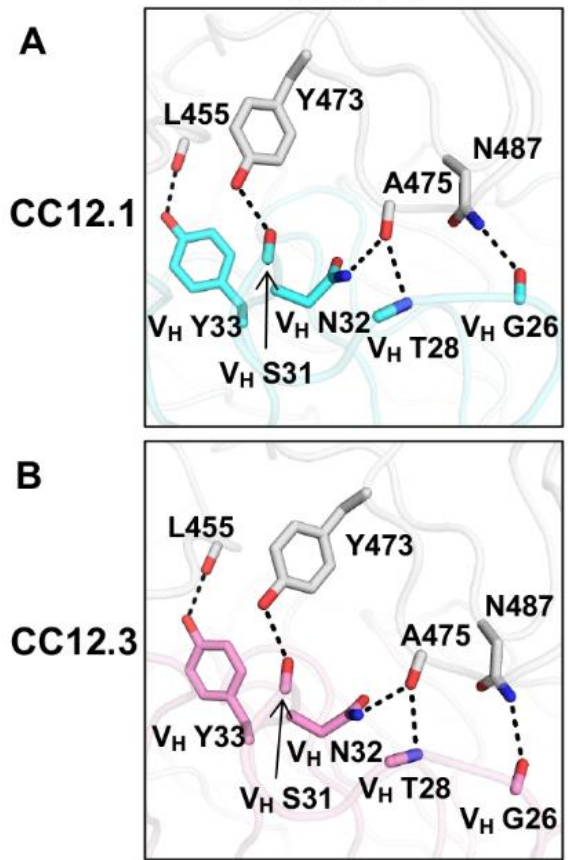

C

B38

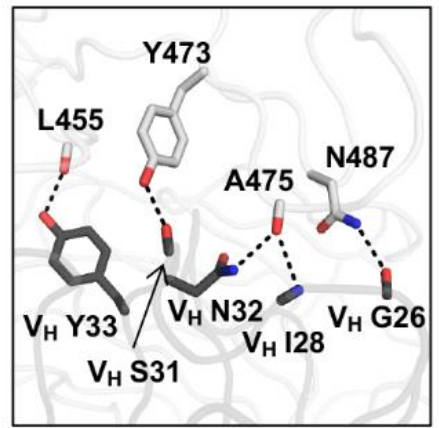

D

ACE2

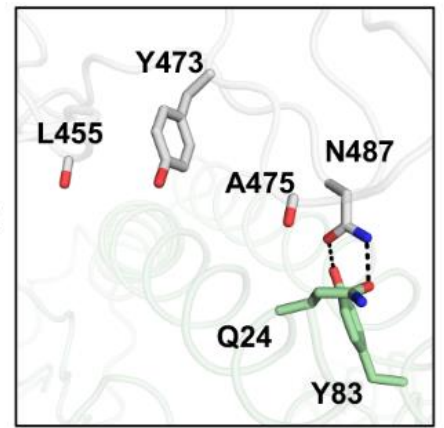

CDR H2
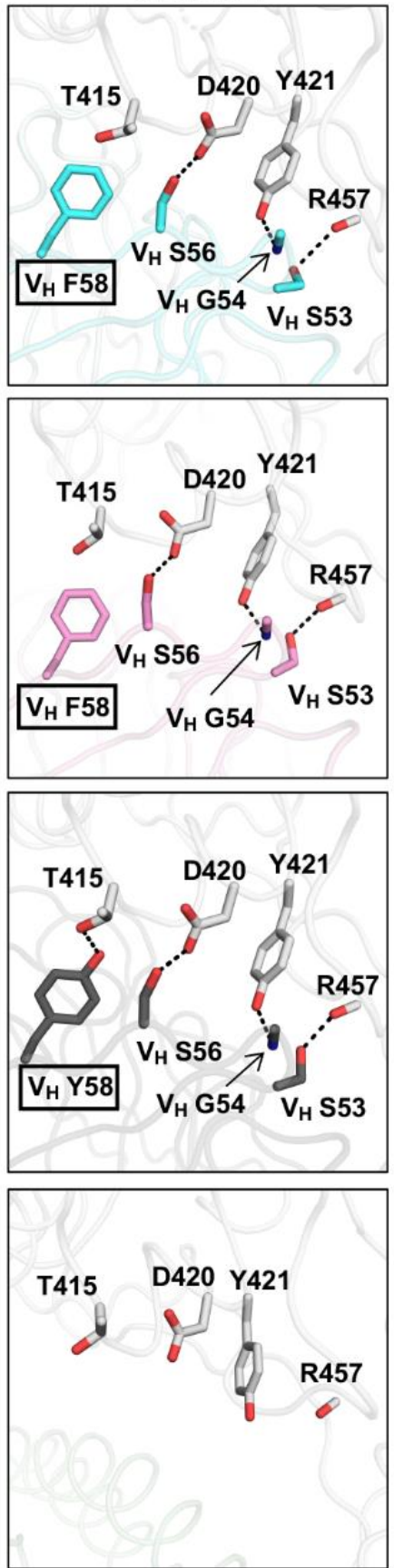

CDR H3
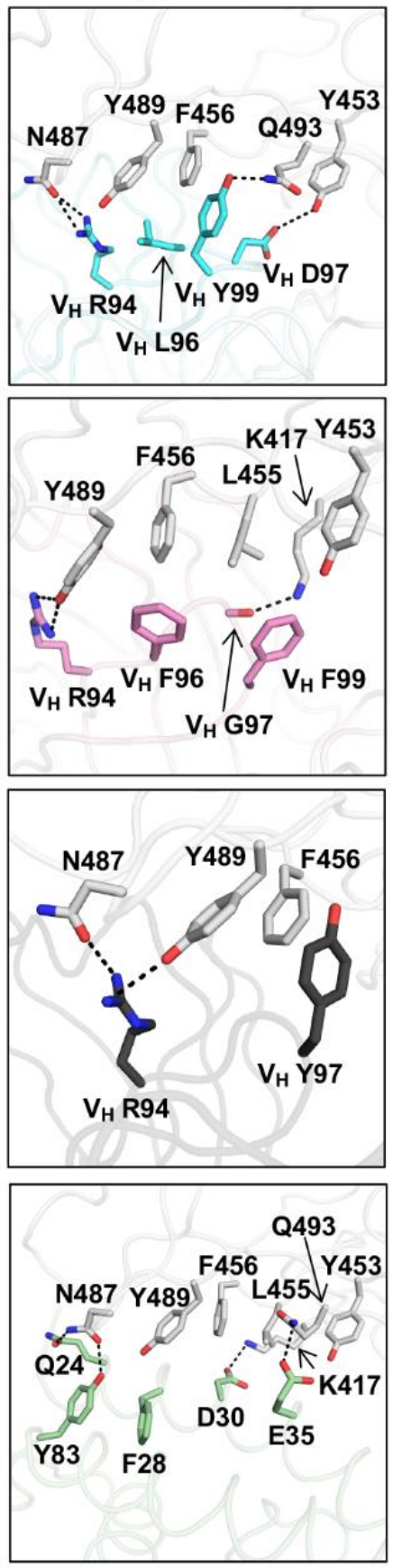

Fig. 3. Interactions between the RBD and heavy chain CDR loops. (A to C) Highly similar interaction modes between SARS-CoV-2 RBD and the antibody CDR $\mathrm{H} 1$ and $\mathrm{H} 2$ loops, but not the H3 loop, are observed for (A) CC12.1, (B) CC12.3, and (C) B38 (PDB 7BZ5) (23). The RBD is in white and antibody residues in cyan, pink, and dark gray, respectively. Oxygen atoms are in red, and nitrogen atoms in blue. Hydrogen bonds are represented by dashed lines. (D) The interaction between ACE2 (green) and residues of the RBD (PDB $6 \mathrm{MOJ})(12)$ that are shown in (A) to (C). 


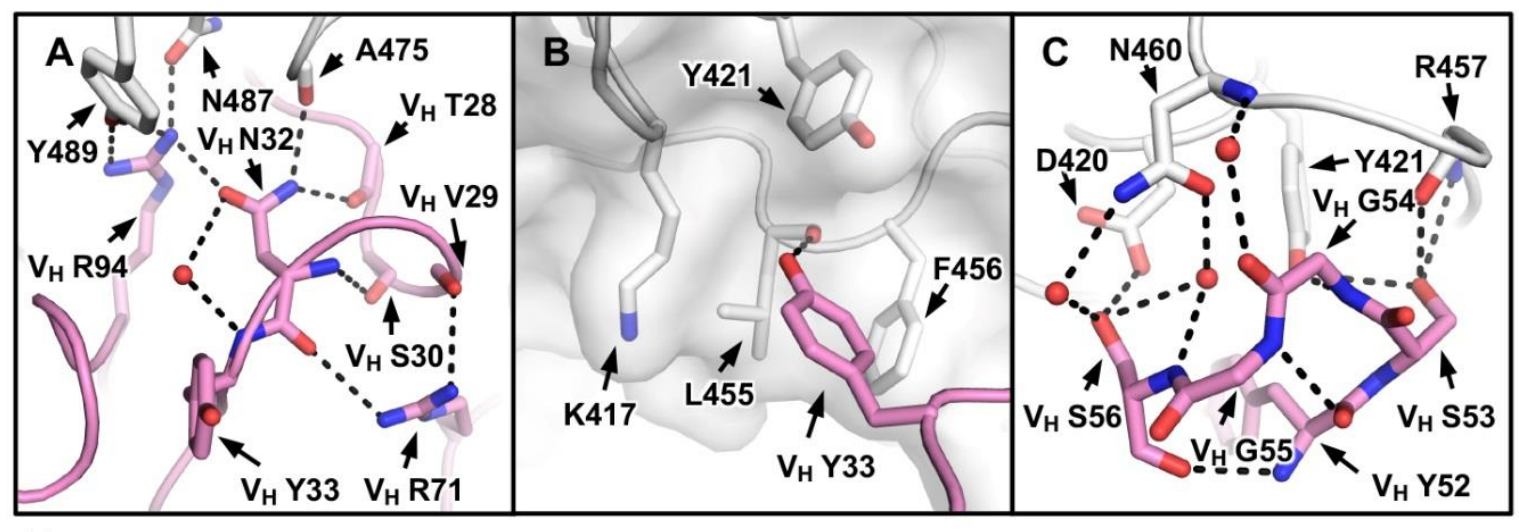

D

CC12.1
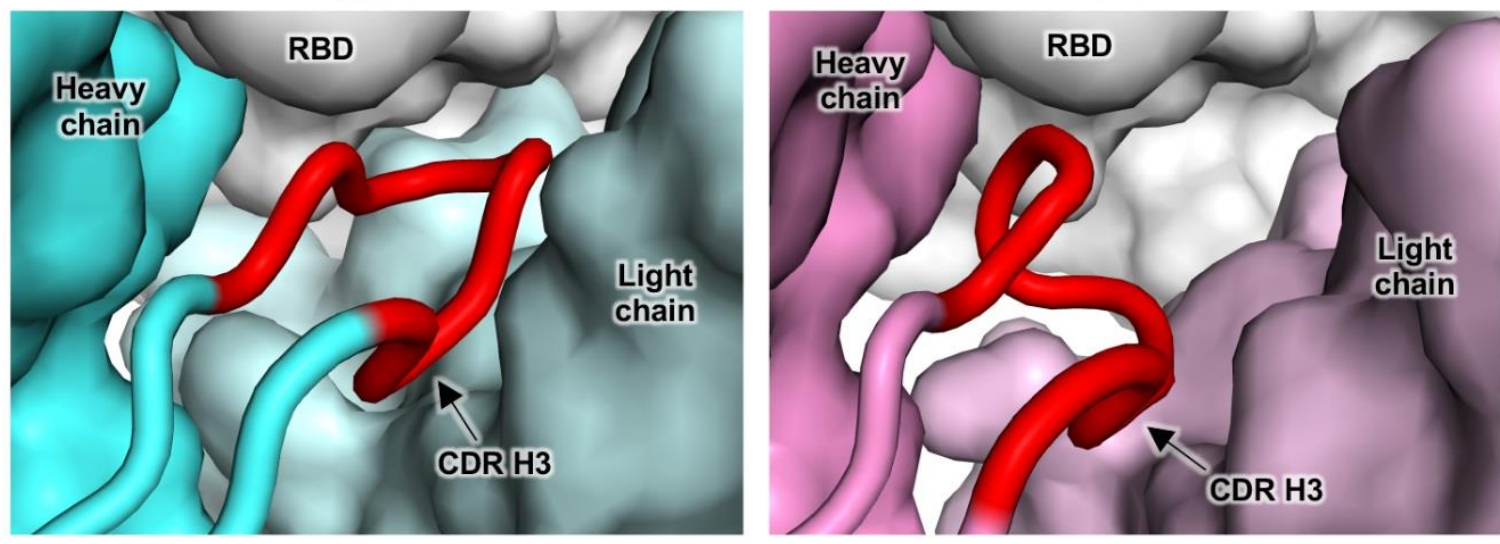

Fig. 4.Two IGHV3-53 germline-encoded motifs with a short CDR H3. (A) The extensive hydrogen bond network that involves $V_{H} N 32$ of the NY motif in CDR H1 is illustrated. (B) The hydrophobic cage interaction between the RBD and $V_{H} Y 33$ of the NY motif in CDR H1 is shown. (C) The hydrogen bond network that involves the SGGS motif in CDR H2 is highlighted. CC12.3 is shown here because its structure is at higher resolution than CC12.1. (D) CDR H3 length is constrained to fit in a relatively small pocket on the RBD surface. The heavy and light chains of CC12.1 (cyan), and the RBD (white) are shown in surface representation, with CDR H3 (red) highlighted in cartoon representation in the left panel. CC12.3 (pink) is shown in the right panel in the same representation. 